\title{
Improved Body Flexibility Following Removal of a Miniscrew Implant
}

\author{
Yoshiro Fujii \\ Shin Kobe Dental Clinic, Kobe, Japan \\ Email: shin-kobe-dentalclinic@s9.dion.ne.jp
}

How to cite this paper: Fujii, F. (2016) Improved Body Flexibility Following Removal of a Miniscrew Implant. Open Journal of Stomatology, 6, 228-235.

http://dx.doi.org/10.4236/ojst.2016.611028

Received: October 18, 2016

Accepted: November 5, 2016

Published: November 10, 2016

Copyright (๑) 2016 by author and Scientific Research Publishing Inc. This work is licensed under the Creative Commons Attribution International License (CC BY 4.0).

http://creativecommons.org/licenses/by/4.0/

\begin{abstract}
A 65-year-old woman, who had been suffering from inflexibility, neck and eye pain as well as general discomfort and stiffness, experienced an improvement in her symptoms upon the removal of a dental miniscrew implant. However, her symptoms returned when the implant was placed near her foot. Her symptoms continued to improve for 6 months. We hypothesize that the cause of her symptoms is linked to electromagnetic waves attracted by the implant. However, the exact underlying mechanism remains unclear, and further research is required in cooperation with the dental, medical, and related fields.
\end{abstract}

\section{Keywords}

Dental Implant, Electromagnetic Waves, Body Flexibility, Electromagnetic Hypersensitivity

\section{Introduction}

A dental implant is a surgical structure that connects to the jaw or skull bone to support a dental prosthesis, such as a crown, bridge, denture, or orthodontic appliance. Risks and complications associated with implant therapy have been divided into those that occur during surgery (e.g., an infection at the implant site; injury or damage to the surrounding structures, such as other teeth or blood vessels; nerve damage, which can cause pain, numbness, or tingling in natural teeth, gums, lips or chin; and sinus problems when dental implants placed in the upper jaw protrude into the sinus cavity) [1], within the first 6 months following surgery (including an infection and failure to osseointegrate), and over the long-term (including peri-implantitis and mechanical failure) [2]. In the presence of healthy tissues, a well-osseointegrated implant with appropriate biomechanical loads can have long-term success rates of $93 \%-98 \%$ for the fixture [3] [4] [5] and a lifespan of 10 - 15 years for the prosthetic teeth [6]. However, even 
if an implant is well osseointegrated, it may attract harmful electromagnetic waves, resulting in many adverse systemic conditions [7] [8] [9]. A miniscrew implant has a peculiar shape compared with other types of implants and is primarily used as an orthodontic anchor. Miniscrew implants can provide stationary anchorage for various tooth movements and make it possible to move the tooth in directions that are impossible using traditional orthodontic mechanics. On the other hand, the clinical use of miniscrew anchorage includes some risks (i.e., screw fracture, damage to the soft tissues, and injury to hard tissues [10]. However, the systemic effects of miniscrew implants are not well established. This study presents a case in which many affected body conditions improved after the removal of a miniscrew implant.

\section{Case Presentation}

5 years prior to this study, the patient (a 65-year-old woman) received a miniscrew implant in her right lower jaw to do the orthodontics of the residual teeth, before inserting a partial denture to compensate for missing teeth. However, she began experiencing symptoms of inflexibility, neck and eye pain as well as general discomfort and stiffness after receiving a dental miniscrew implant.

At the first visit to the dental clinic, the miniscrew was implanted into the molar portion of her right lower jaw (Figure 1, Figure 2). However, her treatment was discontinued because of her symptoms, and therefore, no orthodontic appliance or permanent prosthesis was placed on the implant. There was no evidence of pathology, such as inflammation surrounding the implant or local subjective symptoms (e.g., pain). Although the dentist in charge denied the relationship between the implantation and body issues, the author removed the implant by twisting it out using a plier under topical anesthesia (Figure 3, Figure 4). Immediately after removing the implant, the pa-

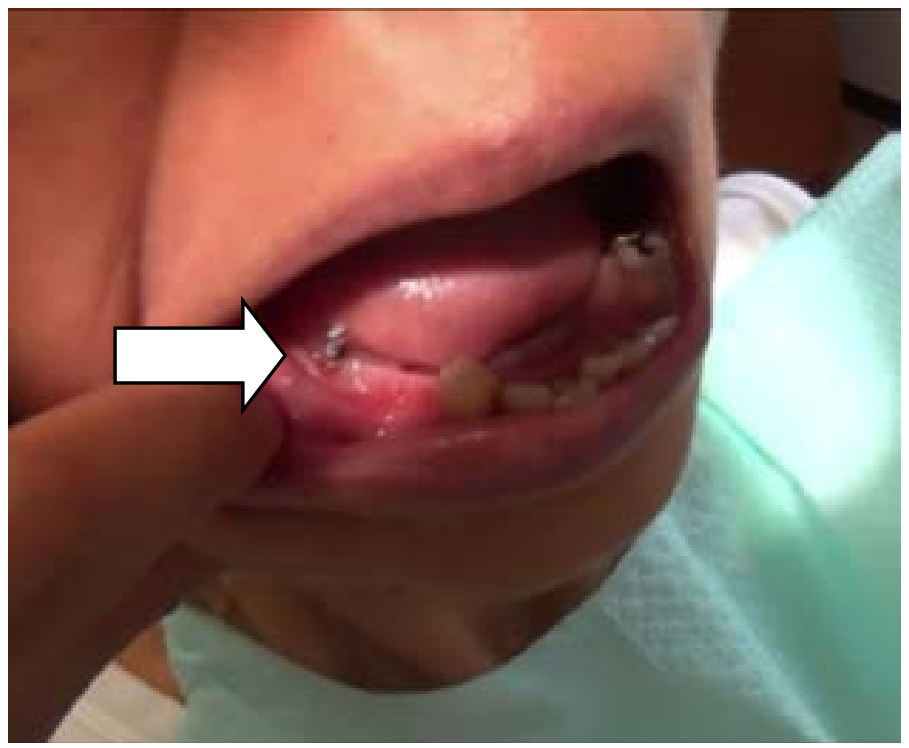

Figure 1. The implanted miniscrew in the molar portion of the patient's right lower jaw (indicated by the arrow). 


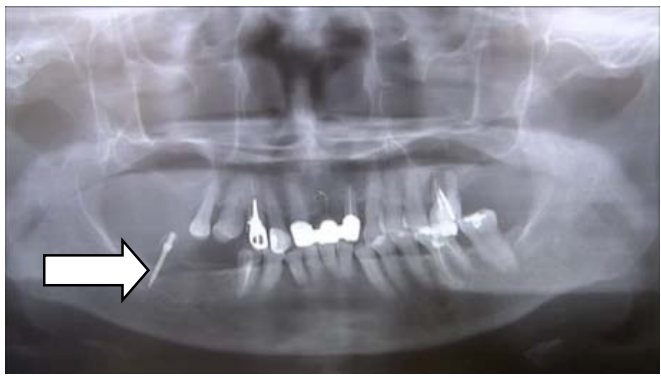

Figure 2. Implanted miniscrew displayed as a panoramic radiograph image (arrow).

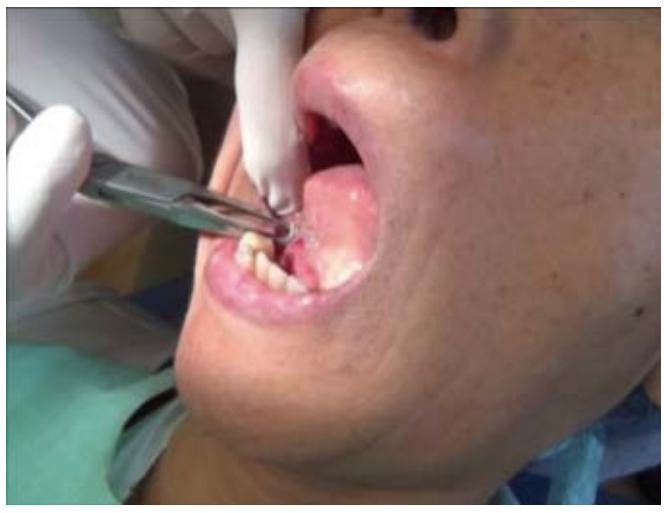

Figure 3. The implant was removed by twisting it out with a plier under topical anesthesia.

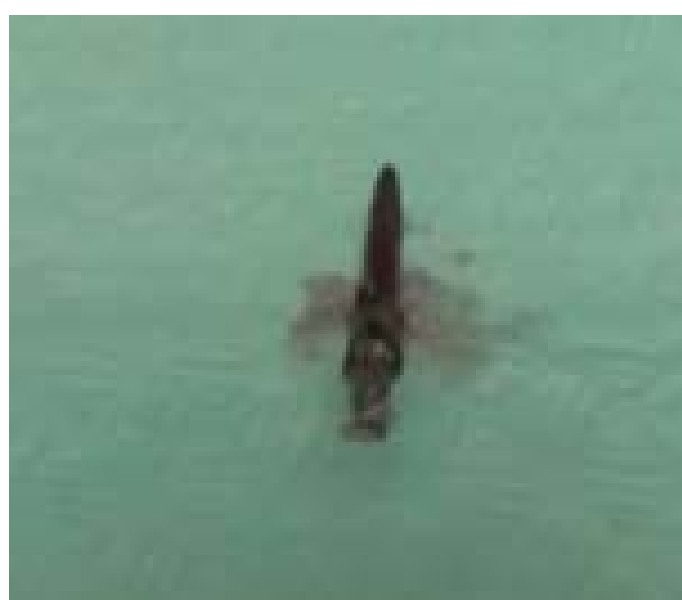

Figure 4. The removed implant.

tient's symptoms improved. In particular, her flexibility noticeably increased (Figure 5). However, she became less flexible when the removed implant was placed near her foot (Figure 6). When the implant was moved away, she regained flexibility. Following the removal of the implant, the author fitted the patient with a partial denture. Her body flexibility continued to improve over the next 6 months (Figure 7). She received no other treatment to the author's knowledge. 


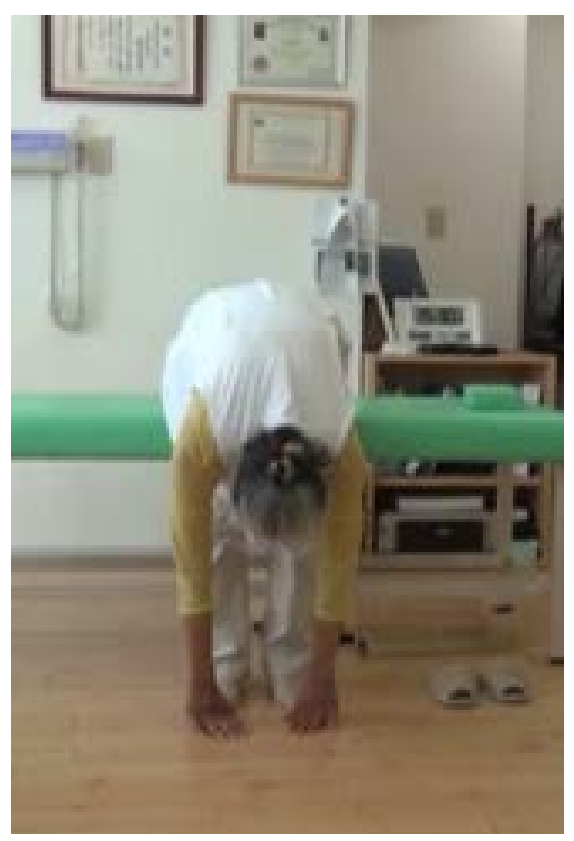

Figure 5. The patient could touch the floor easily after the implant was removed.

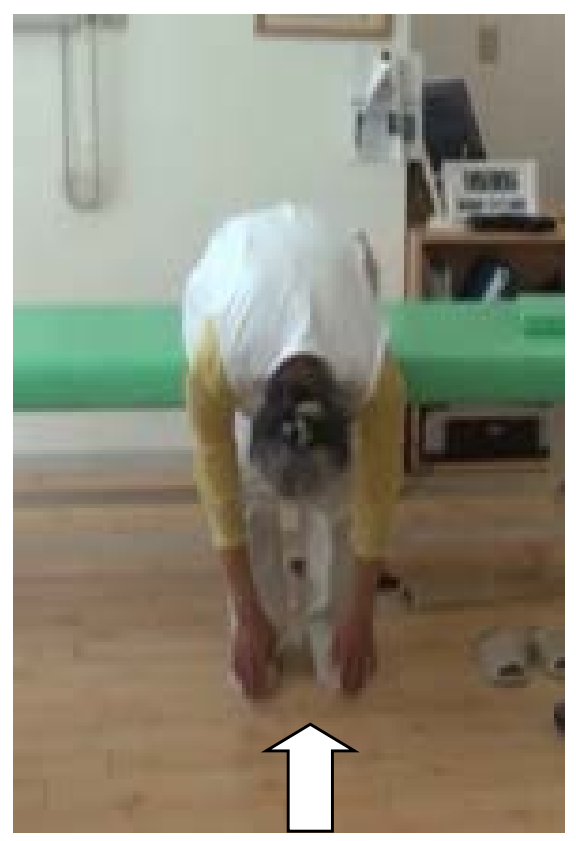

Figure 6. The subject could not touch the floor when the removed implant was placed near her feet (indicated by the arrow).

\section{Discussion}

Through the development of electronic technology, electronic devices, such as cell phones or personal computers (PCs) have spread worldwide in recent years [11] [12]. However, there have been several reports of physical abnormalities occurring because 


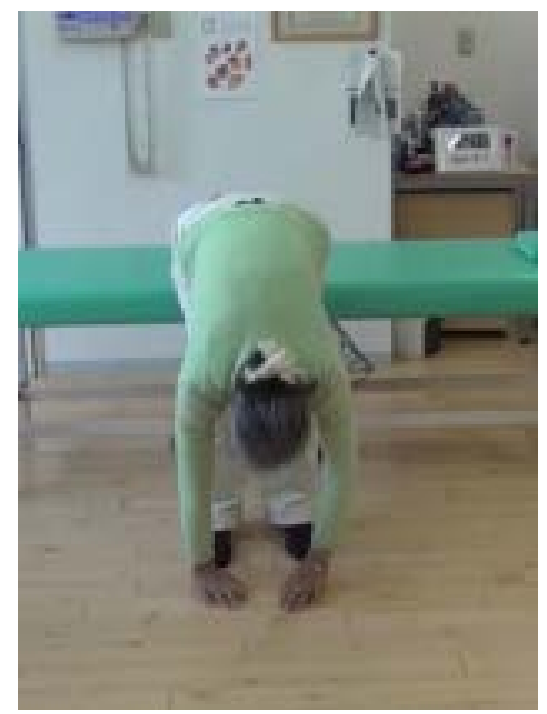

Figure 7. Flexibility continued to improve 6 months after the removal of the miniscrew implant.

of electromagnetic waves emitted by such electronic devices [13]-[20]. In addition, the incidence of adverse biological effects due to electromagnetic waves may be increasing. Such unpleasant symptoms are termed as electromagnetic hypersensitivity. This condition includes many symptoms, such as headaches, fatigue, tinnitus, dizziness, memory loss, irregular heartbeats, and dermatological symptoms, which are considered to be caused by electromagnetic hypersensitivity [21] [22] [23] [24] [25].

There have been previous reports of a case in which dizziness and joint mobility disorders were induced by harmful electromagnetic waves collected by a dental onlay [26] and a case in which balance dysregulation and dizziness were induced by harmful electromagnetic waves collected by a dental amalgam filling [27]. Cases in which dental implants may have collected harmful electromagnetic waves have also been reported [7] [8] [9] [28]. Similar to the aforementioned cases, the miniscrew implant described in the present case may have collected harmful electromagnetic waves, resulting in the patient's reported symptoms. However, this case also clarified that a miniscrew implant might collect harmful electromagnetic waves resulting in several types of physical symptoms because the patient reported that she was completely healthy before receiving the miniscrew implant and that she had no other health problems. Furthermore, the electromagnetic field emitted by a commercial cell phone affects the regional cerebral flow in humans, suggesting that electromagnetic waves may induce changes in neuronal activity [29].

Despite evidence supporting an array of possibilities, the underlying mechanism of the patient's symptoms has not been clarified, and additional research is required in cooperation with the dental, medical, and related fields in order to adequately address this issue.

The actual experiment conducted in this case can be observed in the YouTube video: 
"Body flexibility regaining after an implant removal".

https://www.youtube.com/watch?v=zu-XVZNWFts (last accessed 10/Oct/20156).

\section{Conclusion}

Miniscrew implantation is very useful for orthodontic treatment. However, this case report showed that many systemic symptoms, such as neck pain, eye pain, discomfort, shoulder stiffness, and body stiffness improved after removal of the miniscrew implant. The results suggest that harmful electromagnetic waves collected by the implant can affect the body. Accordingly, testing for the adverse effects of electromagnetic waves is required before dental implant surgery. Further research involving multidisciplinary cooperation may shed light on the underlying mechanisms.

\section{Statement}

The patient orally consented to publication.

\section{References}

[1] Mayo Clonic Staff (2016) Dental Implant Surgery Risks. Mayo Clinic. http://www.mayoclinic.org/tests-procedures/dental-implant-surgery/basics/risks/prc-20009 $\underline{052}$

[2] Esposio, M., Hirsch, J.M., Lekholm, U. and Thomsen, P. (1998) Biological Factors Contributing to Failures of Osseointegrated Oral Implants. (II). Etiopathogenesis. European Journal of Oral Sciences, 106, 721-764. http://dx.doi.org/10.1046/j.0909-8836..t01-6-.x

[3] Papaspyridakos, P., Mokti, M., Chen, C.J., Benic, G.I., Gallucci, G.O. and Chronopoulos, V. (2013) Implantand Prosthodontic Survival Rates with Implant Fixed Complete Dental Prostheses in the Edentulous Mandible after at Least 5 Years: A Systematic Review. Clinical Implant Dentistry and Related Research, 11, 705-717.

[4] Berglundh, T., Persson, L. and Klinge, B. (2002) A Systematic Review of the Incidence of Biological and Technical Complications in Implant Dentistry Reported in Prospective Longitudinal Studies of at Least 5 Years. Journal of Clinical Periodontology, 29, 197-212. http://dx.doi.org/10.1034/j.1600-051X.29.s3.12.x

[5] Pjetursson, B.E., Thoma, D., Jung, R., Zwahlen, M. and Zembic, A. (2012) A Systematic Review of the Survival and Complication Rates of Implant-Supported Fixed Dental Prostheses (FDPs) after a Mean Observation Period of at Least 5 Years. Clinical Oral Implants Research, 23, 22-38. http://dx.doi.org/10.1111/j.1600-0501.2012.02546.x

[6] Bozini, T., Petridis, H., Garefis, K. and Garefis, P. (2011) A Meta-Analysis of Prosthodontic Complication Rates of Implant-Supported Fixed Dental Prostheses in Edentulous Patients after an Observation Period of at Least 5 Years. The International Journal of Oral \& Maxillofacial Implants, 26, 304-318.

[7] Fujii, Y. (2012) Do Dental Implants Cause Scoliosis? Case Report. Personalized Medicine Universe, 1, 79-80. http://dx.doi.org/10.1016/j.pmu.2012.05.012

[8] Fujii, Y. (2014) Sensation of Balance Dysregulation Caused/Aggravated by a Collection of Electromagnetic Waves in a Dental Implant. Open Journal of Antennas and Propagation, 2, 29-35. http://dx.doi.org/10.4236/ojapr.2014.23004

[9] Fujii, Y. (2016) Improvement of Systemic Symptoms after Dental Implant Removal. Open Journal of Stomatology, 6, 37-46. http://dx.doi.org/10.4236/ojst.2016.62005 
[10] Kuroda, S. and Tanaka, E. (2014) Risks and Complications of Miniscrew Anchorage in Clinical Orthodontics. Japanese Dental Science Review, 50, 79-85.

http://dx.doi.org/10.1016/j.jdsr.2014.05.001

[11] Geser, H. (2004) Towards a Sociological Theory of the Mobile Phone, Release 3.0. University of Zurich, Zurich. http://socio.ch/mobile/t_geser1.htm/

[12] Van Dijk, J. and Hacker, K. (2003) The Digital Divide as a Complex and Dynamic Phenomenon. The Information Society, 19, 315-326. http://dx.doi.org/10.1080/01972240309487

[13] Fujii, Y. (2014) Holistic Dentistry (Holistic Dental Treatment). http://www.holistic-dentistry.net/blog/2013/07/entry_242/

[14] Aalto, S., Haarala, C., Brück, A., Sipilä, H., Hämäläinen, H. and Rinne, J.O. (2006) Mobile Phone Affects Cerebral Blood Flow in Humans. Journal of Cerebral Blood Flow and Metabolism, 26, 885-900. http://dx.doi.org/10.1038/sj.jcbfm.9600279

[15] Feychting, M., Jonsson, F., Pedersen, N.L. and Ahlbom, A. (2003) Occupational Magnetic Field Exposure and Neurodegenerative Disease. Epidemiology, 14, 413-419. http://dx.doi.org/10.1097/01.EDE.0000071409.23291.7b

[16] Håkansson, N., Gustavsson, P., Johansen, C. and Floderus, B. (2003) Neurodegenerative Diseases in Welders and Other Workers Exposed to High Levels of Magnetic Fields. Epidemiology, 14, 420-426. http://dx.doi.org/10.1097/01.ede.0000078446.76859.c9

[17] Ahlbom, A. (2001) Neurodegenerative Diseases, Suicide and Depressive Symptoms in Relation to EMF. Bioelectromagnetics Supplement, 5, 132-143. http://dx.doi.org/10.1002/1521-186X(2001)22:5+<::AID-BEM1029>3.0.CO;2-V

[18] Linet, M.S., Hatch, E.E., Kleinerman, R.A., Robison, L.L., Kaune, W.T., Friedman, D.R., et al. (1997) Residential Exposure to Magnetic Fields and Acute Lymphoblastic Leukemia in Children. The New England Journal of Medicine, 337, 1-7. http://dx.doi.org/10.1056/NEJM199707033370101

[19] Röösli, M., Moser, M., Baldinini, Y., Meier, M. and Braun-Fahrländer, C. (2007) Symptoms of Ill Health Ascribed to Electromagnetic Field Exposure-A Questionnaire Survey. International Journal of Hygiene and Environmental Health, 207, 141-150. http://dx.doi.org/10.1078/1438-4639-00269

[20] Edelstyn, N. and Oldershaw, A. (2002) The Acute Effects of Exposure to the Electromagnetic Field Emitted by Mobile Phones on Human Attention. Neuroreport, 13, 119-121. http://dx.doi.org/10.1097/00001756-200201210-00028

[21] Rea, W., Pan, Y., Yenyves, E., Sujisawa, I., Suyama, H., Samadi, N., et al (1991) Electromagnetic Field Sensitivity. Journal of Bioelectricity, 10, 241-256.

http://www.feb.se/emfguru/Ehs/electromagnetic-sensitivity.html http://dx.doi.org/10.3109/15368379109031410

[22] Rubin, G.J., Das Munshi, J. and Wessely, S. (2005) Electromagnetic Hypersensitivity: A Systematic Review of Provocation Studies. Psychosomatic Medicine, 67, 224-232. http://dx.doi.org/10.1097/01.psy.0000155664.13300.64

[23] Rubin, G.J., Das Munshi, J. and Wessely, S. (2006) A Systematic Review of Treatments for Electromagnetic Hypersensitivity. Psychosomatic Medicine, 75, 12-18.

[24] Norbert, L. (2009) Electromagnetic Hypersensitivity. Advances in Electromagnetic Fields in Living Systems, 5, 167-197. http://dx.doi.org/10.1007/978-0-387-92736-7_5

[25] Kimata, H. (2005) Microwave Radiation from Cellular Phones Increases Allergen-Specific IgE Production. Allergy, 60, 838-839. http://dx.doi.org/10.1111/j.1398-9995.2005.00802.x

[26] Fujii, Y. (2015) Dental Treatment for Dizziness and Joint Mobility Disorder Caused by Harmful Electromagnetic Waves. Open Journal of Antennas and Propagation, 3, 1-7. 
http://dx.doi.org/10.4236/ojapr.2015.31001

[27] Fujii, Y. (2015) Electromagnetic Waves Collected by a Dental Amalgam Filling Induced Balance Dysregulation and Dizziness over a Period Exceeding 10 Years. Open Journal of Stomatology, 5, 235-242. http://dx.doi.org/10.4236/ojst.2015.510029

[28] Fujii, Y. (2014) Sense of Balance Disorder Caused by Electromagnetic Waves Collected by a Dental Implant. Acupuncture and Electro-Therapeutics Research, 39, 379.

[29] Aalto, S., Haarala, C., Brück, A., Sipilä, H., Hämäläinen, H. and Rinne, J.O. (2006) Mobile Phone Affects Cerebral Blood Flow in Humans. Journal of Cerebral Blood Flow and Metabolism, 26, 885-900. http://dx.doi.org/10.1038/sj.jcbfm.9600279

Submit or recommend next manuscript to SCIRP and we will provide best service for you:

Accepting pre-submission inquiries through Email, Facebook, LinkedIn, Twitter, etc. A wide selection of journals (inclusive of 9 subjects, more than 200 journals)

Providing 24-hour high-quality service

User-friendly online submission system

Fair and swift peer-review system

Efficient typesetting and proofreading procedure

Display of the result of downloads and visits, as well as the number of cited articles

Maximum dissemination of your research work

Submit your manuscript at: http://papersubmission.scirp.org/

Or contact ojst@scirp.org 